\title{
BMJ Open Social determinants of HIV infection, hotspot areas and subpopulation groups in Ethiopia: evidence from the National Demographic and Health Survey in 2011
}

\author{
Yihunie Lakew, ${ }^{1}$ Susan Benedict, ${ }^{2}$ Demewoz Haile ${ }^{3}$
}

To cite: Lakew Y, Benedict S, Haile D. Social determinants of HIV infection, hotspot areas and subpopulation groups in Ethiopia: evidence from the National Demographic and Health Survey in 2011. BMJ Open 2015;5:e008669.

doi:10.1136/bmjopen-2015008669

- Prepublication history for this paper is available online. To view these files please visit the journal online (http://dx.doi.org/10.1136/ bmjopen-2015-008669).

Received 6 May 2015 Revised 14 August 2015 Accepted 17 October 2015

\section{CrossMark}

\footnotetext{
${ }^{1}$ Ethiopian Public Health Association, Addis Ababa, Ethiopia

${ }^{2}$ The University of Texas Health Science Center at Houston, School of Nursing, Houston, Texas, USA

${ }^{3}$ Department of Reproductive Health, College of Medicine and Health Sciences, Bahir Dar University, Bahir Dar, Amhara Region, Ethiopia
}

Correspondence to Yihunie Lakew; yihunierh@yahoo.com

\section{ABSTRACT}

Objective: This study identifies social determinants of HIV infection, hotspot areas and subpopulation groups in Ethiopia.

Design: The study used data from the 2011 Ethiopian Demographic and Health Survey (EDHS). Sample blood tests from the finger pricks collected on filter paper cards were labelled with a barcode unique to each respondent. Spatial scan statistics and geographic information system tools were used to map hotspot areas of HIV prevalence. Bivariate and multivariable logistic regression models were used to identify social determinants of HIV infection.

Population: A total of 30625 adults (16 515 women and 14110 men) were included from 11 administrative states of Ethiopia.

Main outcome measures: Laboratory-confirmed HIV serostatus is the main outcome variable.

Results: HIV prevalence reached $10-21 \%$ in the central, eastern and western geographic clusters of Ethiopia. Multivariable analysis showed that individuals who were in the middle, richer and richest wealth quintiles had increased odds of having HIV over those in the poorest quintile. Adults who had primary, secondary and higher educational levels had higher odds of being HIV positive than non-educated individuals. The odds of having HIV were higher among adults who had multiple lifetime sexual partners than those with a single partner. An increasing odds of HIV infection were observed among adults in the age groups of 25-29, 30-34, 35-39 and 40-45 years compared with adults in the age group of $45-49$ years. Merchants had higher odds of being HIV positive than those who were not employed. The odds of having HIV were higher among urban residents and females than among rural residents and males, respectively.

Conclusions: This study found statistically significant HIV concentrations in administrative zones of central, eastern and western Ethiopia. Geospatial monitoring and targeting of prevention strategies for specific population groups is recommended.

\section{Strengths and limitations of this study}

- One of the strengths of this study is the use of a nationwide laboratory-confirmed HIV serostatus data. Therefore, the study findings can be used to inform policy and programme actors at subnational and regional levels.

- However, the study has certain limitations. Some regions and Ethiopian Demographic and Health Survey (EDHS) clusters had small sample sizes, which raises the question about the accuracy of prevalence estimates per region, so that those should be interpreted with caution. As the study was a secondary data analysis, it lacks other important social determinant variables which could be associated with risk of HIV infection.

- This study also shares the limitation of the cross-sectional study design which prohibits confirmation of cause and effect relationships.

\section{INTRODUCTION}

HIV/AIDS has been documented as one of the major public health challenges in the world. $^{1}$ Globally, there were approximately 35.0 million people living with HIV at the end of 2013 with 2.1 million people newly infected. The sub-Saharan region of Africa is the most affected in the world with 24.7 million people living with HIV in $2013 .^{2}$ This region accounts for almost $70 \%$ of the global total of new HIV infections despite of having only a $13 \%$ share of the world's population. ${ }^{2}$ Ethiopia is one of the sub-Sahara African countries shared the burden of HIV epidemics. ${ }^{3}$ There were totally 759268 people living with HIV and 80000 HIV-infected children in Ethiopia in the year 2012. ${ }^{4}$ The national HIV prevalence among adults in Ethiopia has declined from $4.5 \%$ between 1998 and $1999^{1}$ to $1.5 \%$ in $2011,^{5}$ which is an encouraging achievement for the country. 
Although estimates suggest that the rate of new HIV infection is declining in many African settings, ${ }^{2}$ the HIV incidence remains unacceptably high with striking subpopulation and geographic differences. ${ }^{6}$ The HIV epidemic has been showing remarkable variations across population subgroups, ${ }^{7}$ regions and countries, ${ }^{6} 8$ at the subnational level between provinces ${ }^{9}$ and within subdistricts. ${ }^{10}$ The geographical structure of HIV epidemic is the consequence of drivers of the epidemic and the availability of susceptible population to the infection. ${ }^{11}$ Strongest clustering has been observed in countries with a low national prevalence of HIV infection. ${ }^{11}$ The "know your epidemic' concept recognises this geographical feature as a key strategy in identifying populations at higher risk of HIV infection and in which prevention interventions should be targeted. ${ }^{12}$

The HIV/AIDS epidemic in Ethiopia is often classified as 'generalised' among the adult population with significant heterogeneity among regions and population groups. ${ }^{13}$ The rural epidemic appears to be relatively widespread but heterogeneous with most rural areas having a relatively low prevalence of HIV infection. ${ }^{13}$ In many African countries including Ethiopia, the concept of concentrated subepidemics within a generalised epidemic context has been relatively neglected topic to date. ${ }^{14}$ Mapping hotspot areas, identifying social determinants and affected population groups, especially in resource-limited settings, would assist in targeting and prioritising interventions. ${ }^{15}$ The hotspot areas would be further examined for unobserved or unknown risk factors which are driving the HIV epidemic. Monitoring a localised epidemic is, therefore, essential for more effective prevention strategies $^{16}$ in Ethiopia even though adult HIV prevalence has declined at the national level, little information is available about the subgeographic areas and certain subpopulation groups in the country. We hypothesise that low national prevalence of HIV infection hides the localised epidemics in Ethiopia. Therefore, this study aimed to identify social determinants of HIV infection, hotspot areas, and subpopulation groups to effectively target interventions in the country which has limited resources available.

\section{METHODS AND MATERIALS}

\section{Data type and study design}

This analysis used data from the 2011 Ethiopian Demographic and Health Survey (EDHS). The survey followed an international Demographic and Health Survey (DHS) methodology and is conducted at 5 years interval. The EDHS was designed to provide population and health indicators at the national (urban and rural) and regional levels. The 2011 EDHS samples were selected using a stratified and two-stage cluster sampling design. The survey included 624 samples of enumeration areas (clusters), of which 187 were in urban areas and 437 were in rural areas. A representative sample of
16702 households were interviewed in all 11 administrative regions and 85 zones. Of these, 11590 households interviewed were from rural areas. A total of 30625 adults between 15 and 59 years of age were included, among which 16515 respondents were women. Overall, $86 \%$ of respondents who were eligible for testing were interviewed and consented to HIV testing. Four per cent of respondents refused to be tested for HIV and did not provide blood sample. The response rates for HIV testing were $89 \%$ for women and $82 \%$ for men. The detailed methodology is found elsewhere. ${ }^{17}$

\section{Data extraction}

The 2011 EDHS data sets were downloaded in SPSS format with permission from the Measure DHS website (http://www.dhs program.com). After understanding the detailed data sets and coding, further data recoding was carried out. Social determinants and HIV prevalence indicator variables were extracted from male and female data sets. Data sets of HIV test results, sociodemographic characteristics of respondents and Global Positioning System (GPS) coordinates of EDHS clusters were merged accordingly for this analysis.

\section{Measurement of variables}

Sample blood tests with voluntary HIV counselling were carried out to provide HIV data for the 2011 EDHS. Five blood spots from the finger pricks were collected on a filter paper card labelled with a barcode unique to each respondent. The detailed procedures can be accessed elsewhere. ${ }^{17}$ The barcodes identifying the HIV test results were linked with individual respondent data sets.

On the basis of the literature review ${ }^{16}{ }^{18-20}$ and data in the 2011 EDHS, social determinant variables were identified. For this study, the term 'social determinants' encompass the socioeconomic, cultural, residence and lifestyle conditions of people that may predispose to HIV infection. The chosen variables to potentially associate with HIV were wealth index, age, occupation, comprehensive knowledge of HIV, use of alcohol or khat, migration, religion, location of residence including administrative region, education, mass media exposure including reading newspaper, listening to radio and television, gender, total number of lifetime sexual partners and marital status. These variables were selected that guided by literature review. ${ }^{19} 21-24$

\section{Statistical analysis}

The spatial scan statistics (SaTScan) software (V.9.1, http://www.satscan.org) was used to detect the potential clustering of HIV cases. ${ }^{25}$ The basic idea of SaTScan is to allow circular windows of various sizes to range across the study areas. At each location, the rate of disease inside the window is compared with that outside of it. For a given cluster (circular window), the software calculates the probability of a data point being a case inside 
or outside the circle under consideration. For each circle, a likelihood ratio is computed for the alternative hypothesis that there is an increased risk of disease inside the circle, against the null hypothesis that the risk inside the circle is the same as that outside. In this context, a hotspot cluster is detected within a defined geographical area during a specific timeframe if the area has a disproportionate excess of HIV cases when compared with neighbouring areas under study. While satisfying assumptions of the statistical model, an unusual high or low number of cases in specific spatial areas can be characterised by statistical significance. The sets of potential clusters are then rank ordered according to the magnitude of their likelihood ratio test statistics. The user-defined maximum radius used by SaTScan was set to its default value of $50 \%$, as recommended by Kulldorf. $^{25}$ In order to investigate the sensitivity of SaTScan results to the default setting, we ran the SaTScan spatial scan statistics 10 times, starting with a maximum size of $5 \%$ and increasing the parameter by an interval of $5 \%$ with each run until reaching the default maximum size value of $50 \%$. Results were not affected by the choice of radius selected; we therefore used the default value of $50 \%$ in our analysis.

We also used 'svy' command in STATA V.11 to weight the survey data and perform all types of analyses. Sample weights were applied in order to compensate for the unequal probability of selection between the strata that have been geographically defined as well as for non-responses. A detailed explanation of the weighting procedure can be found in the EDHS methodology report. ${ }^{17}$ Descriptive statistics were used to determine the weighted prevalence of HIV across social determinant variables. Bivariate and multivariable logistic regressions were carried out to determine the factors associated with HIV prevalence. As recommended by Hosmer and Lemeshow, ${ }^{26}$ variables found to be statistically significant at $p$ value $<0.25$ during bivariate analysis could be candidates for multivariable logistic regression model. This $\mathrm{p}$ value cut-off point is important to retain variables that will have potential effects during multivariable analysis. A multicollinearity test was performed and variables with variance inflation factors (VIF) of greater than 10 were excluded from the multivariable analysis. ${ }^{27}$ No variables were found to exceed the VIF value of 10 in the multicollinearity test. All tests were two-sided and a $p$ value $<0.05$ was considered statistically significant in the multivariable statistical model. Crude and adjusted ORs were calculated with $95 \%$ CI.

\section{Ethical consideration}

The original EDHS data were collected in conformity with international and national ethical guidelines. The data for this study were downloaded and used after the purpose of the analysis was communicated and approved by the Measure DHS.
RESULTS

\section{Characteristics of the study population}

The 2011 EDHS included a total of 30625 adults in the age range of 15-59 years for men and 15-49 years for women. Among the respondents, 53.9\% (16515) were females. About $68.8 \%$ (21 080) respondents were from rural areas. Approximately $42 \%$ of the respondents had not attended formal education while $41 \%$ had primarylevel education. The proportion of Christians (Orthodox, Protestant and Catholic) was $60.7 \%$ followed by Muslims which accounted for $37.5 \%$. The mean age of respondents was 29.0 years with a SD of 10.5 years.

\section{HIV prevalence by sociodemographic characteristics}

The overall prevalence of HIV was $1.5 \%$ with a $1.9 \%$ (95\% CI $(1.70 \%$ to $2.12 \%))$ prevalence rate in females and a $1.1 \%(95 \%$ CI $0.84 \%$ to $1.18 \%)$ prevalence rate in males. The prevalence of HIV in urban settings was $4.3 \%(95 \%$ CI $(3.81 \%$ to $4.81 \%))$ while in rural areas it was $0.7 \%(95 \%$ CI $(0.60 \%$ to $0.81 \%))$. The prevalence of HIV infection was $1.8 \%$ (95\% CI ( $1.62 \%$ to $1.99 \%)$ ) among Christianity religion followers. The prevalence of HIV infection in Gambella administrative region was $6.6 \%(95 \%$ CI $(3.51 \%$ to $12.60 \%))$ followed by administrative cities of Addis Ababa with 5.3\% (95\% CI $(4.14 \%$ to $6.45 \%)$ ) and Dire Dawa with $4.0 \%$ (95\% CI (1.64\% to $9.53 \%)$ ). The lowest prevalence, $1.0 \%$ (95\% CI $(0.83 \%$ to $1.20 \%)$ ), was found in Oromia region. Among the wealth quintiles, the highest prevalence of HIV infection at $4.1 \%(95 \%$ CI $(3.65 \%$ to $4.58 \%))$ was found in the richest wealth quintile. The prevalence of HIV infection among individuals who had attended secondary and higher education level was $2.4 \%$ (95\% CI $(1.95 \%$ to $2.94 \%)$ ). The prevalence of HIV infection in the age group of $35-39$ years was $3.0 \% \quad(95 \%$ CI $(2.47 \%$ to $3.62 \%)$ ) followed by $30-34$ years age group with $2.7 \%$ (95\% CI $(2.18 \%$ to $3.28 \%))$. About $7 \%$ (5.87\% to $8.07 \%$ ) of HIV infection was observed in formerly married adults. Among the different occupational groups, the highest prevalence of HIV was found among mobile workers at $5.7 \%$ (95\% CI $(2.94 \%$ to $9.40 \%)$ ) followed by merchants with $5.4 \%$ (95\% CI $(4.41 \%$ to $6.48 \%)$ ). HIV prevalence was $4.1 \%$ (95\% CI $(2.73 \%$ to $5.81 \%)$ ) among frontline service workers, $2.9 \%$ (95\% CI $(0.10 \%$ to $9.29 \%))$ among construction and engineering workers and $2.7 \%(95 \%$ CI $(2.22 \%$ to $3.24 \%))$ in sales workers (table 1).

\section{Geographic clusters of HIV prevalence in Ethiopia}

As shown on figure 1, the prevalence of HIV reaches up to $10-21 \%$ in certain geographic clusters particularly in the central, eastern and western parts of the country. There are also some clusters with a prevalence of HIV from $4 \%$ to $9 \%$ in northern and southwestern Ethiopia. Most geographic coverages of the country have had an HIV prevalence rate of $<4.5 \%$. There were no EDHS clusters (enumeration areas) included in the peripheral areas of the country, particularly in eastern parts of 
Table 1 HIV prevalence by different socio-demographic characteristics of respondents in Ethiopia, 2011

\begin{tabular}{|c|c|c|c|}
\hline Characteristics of respondents & $\begin{array}{l}\text { HIV prevalence } \\
\text { with } 95 \% \mathrm{Cl}\end{array}$ & $\begin{array}{l}\text { Total weighted } \\
\text { respondents }\end{array}$ & $\begin{array}{l}\text { Weighted number } \\
\text { of HIV Cases }\end{array}$ \\
\hline \multicolumn{4}{|l|}{ Sex } \\
\hline Male & $1.1(0.84$ to 1.18$)$ & 13,642 & 148 \\
\hline Female & $1.9(1.70$ to 2.12$)$ & 14,684 & 283 \\
\hline \multicolumn{4}{|l|}{ Residence } \\
\hline Urban & 4.3 (3.81 to 4.81$)$ & 6,491 & 279 \\
\hline Rural & $0.7(0.60$ to 0.81$)$ & 21,835 & 152 \\
\hline \multicolumn{4}{|l|}{ Religion } \\
\hline Christian & 1.8 (1.62 to 1.99$)$ & 19,716 & 365 \\
\hline Muslim & 0.7 (0.54 to 0.90$)$ & 8,032 & 57 \\
\hline Traditional and others & $1.5(0.75$ to 2.79$)$ & 578 & 9 \\
\hline \multicolumn{4}{|l|}{ Administrative regions } \\
\hline Tigray & 1.8 (1.26 to 2.46$)$ & 1,816 & 33 \\
\hline Afar & 1.9 (0.52 to 3.90$)$ & 236 & 4 \\
\hline Amhara & $1.6(1.34$ to 1.89$)$ & 7,705 & 124 \\
\hline Oromia & $1.0(0.83$ to 1.20$)$ & 10,558 & 106 \\
\hline Somali & $1.6(0.73$ to 2.95$)$ & 555 & 9 \\
\hline Benishangul-gumuz & 1.4 (0.42 to 3.12$)$ & 294 & 4 \\
\hline SNNPR & $1.1(0.85$ to 1.40$)$ & 5,353 & 57 \\
\hline Gambella & 6.6 (3.51 to 12.60$)$ & 123 & 8 \\
\hline Harari & $2.9(0.42$ to 8.01$)$ & 86 & 3 \\
\hline Addis Ababa & $5.3(4.14$ to 6.45 & 1,484 & 78 \\
\hline Dire Dawa & 4.0 (1.64 to 9.53$)$ & 117 & 5 \\
\hline \multicolumn{4}{|l|}{ Wealth Index } \\
\hline Poorest & $0.4(0.25$ to 0.59$)$ & 4,950 & 21 \\
\hline Poorer & $0.5(0.33$ to 0.71$)$ & 5,273 & 24 \\
\hline Middle & $0.7(0.50$ to 0.95$)$ & 5,382 & 39 \\
\hline Richer & $1.1(0.86$ to 1.39$)$ & 5,722 & 61 \\
\hline Richest & 4.1 (3.65 to 4.58$)$ & 6,999 & 286 \\
\hline \multicolumn{4}{|l|}{ Education } \\
\hline Not formal education & 1.1 (0.93 to 1.29$)$ & 12,391 & 136 \\
\hline Primary & $1.6(1.39$ to 1.83$)$ & 12,837 & 205 \\
\hline Secondary and higher & 2.4 (1.95 to 2.94$)$ & 3,738 & 90 \\
\hline \multicolumn{4}{|l|}{ Marital status } \\
\hline Never married & $0.4(0.29$ to 0.55$)$ & 9,199 & 41 \\
\hline Currently married & $1.4(1.24$ to 1.58$)$ & 17,169 & 252 \\
\hline Formerly married & 6.9 (5.87 to 8.07$)$ & 1,958 & 138 \\
\hline \multicolumn{4}{|l|}{ Age groups } \\
\hline $15-19$ & $0.2(0.11$ to 0.33$)$ & 6,362 & 11 \\
\hline $20-24$ & $0.7(0.50$ to 0.97$)$ & 4,871 & 33 \\
\hline $25-29$ & 2.1 (1.73 to 2.52$)$ & 5,041 & 104 \\
\hline $30-34$ & $2.7(2.18$ to 3.28$)$ & 3,283 & 89 \\
\hline $35-39$ & 3.0 (2.47 to 3.62$)$ & 3,342 & 104 \\
\hline $40-44$ & 2.1 (1.49 to 2.66$)$ & 2,199 & 45 \\
\hline $45-49$ & $1.9(1.27$ to 2.43$)$ & 1,975 & 37 \\
\hline $50+$ & $0.7(0.31$ to 1.26$)$ & 1,252 & 8 \\
\hline \multicolumn{4}{|l|}{ Number of life time sexual partners } \\
\hline Single & 0.9 (0.75 to 1.08$)$ & 13,063 & 118 \\
\hline Multiple & 3.7 (3.30 to 4.15$)$ & 7,612 & 282 \\
\hline \multicolumn{4}{|l|}{ Ever alcohol drinking } \\
\hline No & $1.0(0.85$ to 1.17$)$ & 14,727 & 147 \\
\hline Yes & 2.0 (1.78 to 2.24$)$ & 14,229 & 285 \\
\hline \multicolumn{4}{|l|}{ Comprehensive knowledge on HIV } \\
\hline No & 1.5 (1.36 to 1.65$)$ & 27,505 & 413 \\
\hline Yes & $0.3(0.05$ to 0.97$)$ & 676 & 2 \\
\hline \multicolumn{4}{|l|}{ Exposure to mass media } \\
\hline No & $1.0(0.79$ to 1.24$)$ & 7,341 & 73 \\
\hline Yes & $1.7(1.53$ to 1.88$)$ & 21,495 & 365 \\
\hline
\end{tabular}


Table 1 Continued

\begin{tabular}{|c|c|c|c|}
\hline Characteristics of respondents & $\begin{array}{l}\text { HIV prevalence } \\
\text { with } 95 \% \mathrm{Cl}\end{array}$ & $\begin{array}{l}\text { Total weighted } \\
\text { respondents }\end{array}$ & $\begin{array}{l}\text { Weighted number } \\
\text { of HIV Cases }\end{array}$ \\
\hline \multicolumn{4}{|l|}{ Occupational status } \\
\hline Not working including house wives & 1.3 (1.06 to 1.58$)$ & 7,240 & 94 \\
\hline Corporate and general managers & $1.2(0.06$ to 5.54$)$ & 87 & 1 \\
\hline Teaching and associate professions & 2.0 (1.06 to 3.66$)$ & 483 & 10 \\
\hline Health and life science workers & 2.4 (0.64 to 6.60$)$ & 121 & 3 \\
\hline Construction and engineering workers & 2.9 (0.10 to 9.29$)$ & 51 & 1 \\
\hline Front line service workers & 4.1 (2.73 to 5.81$)$ & 640 & 26 \\
\hline Sales workers & 2.7 (2.22 to 3.24$)$ & 3,932 & 106 \\
\hline Agricultural workers & 0.5 (0.37 to 0.65$)$ & 9,692 & 48 \\
\hline Daily laborers & 0.7 (0.49 to 0.99$)$ & 4,258 & 30 \\
\hline Merchants & 5.4 (4.41 to 6.48$)$ & 1,842 & 99 \\
\hline $\begin{array}{l}\text { Mobile workers including drivers, } \\
\text { operators and assemblers }\end{array}$ & 5.7 (2.94 to 9.40$)$ & 199 & 11 \\
\hline Other occupations* & 0.1 (0.03 to 2.48$)$ & 197 & 1 \\
\hline Total & 1.5 (1.35 to 1.63$)$ & 28,326 & 431 \\
\hline
\end{tabular}

Somali administrative region and as a result the HIV prevalence could not be estimated in this analysis.

As indicated in table 2 and figure 2, six clusters were identified during SaTScan analysis; however, only cluster 1 and 2 were statistically significant hotspots with $p$ value at $<0.001$ and 0.003 , respectively. In the first cluster, a total of 164 EDHS enumeration locations were circled within a $258 \mathrm{~km}$ radius. This hotspot covered a total of 24 administrative zones from Oromia, Amhara, Tigray, Afar and Somali administrative regions including Addis Ababa. A total of 252 HIV cases were observed in this hotspot with 2.6 relative risk and $48 \mathrm{log}$ likelihood ratio (LLR) that would be about 153 HIV cases expected. In the second hotspot, only one EDHS enumeration

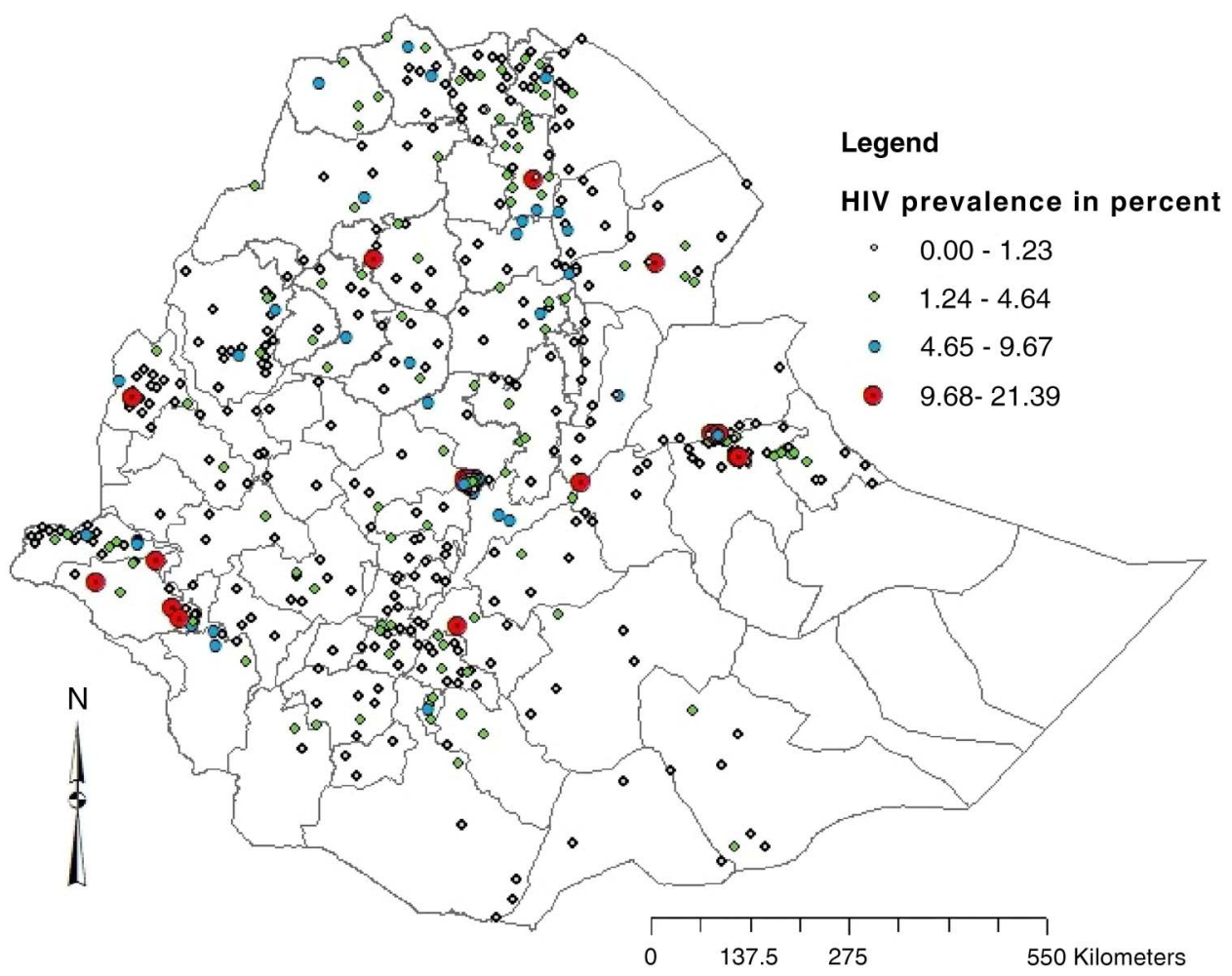

Figure 1 Map showing the prevalence of HIV infection in Ethiopian Demographic and Health Survey (EDHS) cluster areas of Ethiopian Zones, 2011. 
Table 2 Statistical summaries from SaTScan clustering analysis in Ethiopian administrative regions and zones, 2011

\begin{tabular}{|c|c|c|c|c|c|c|c|}
\hline Clusters & Regions/zones in the cluster & $\begin{array}{l}\text { Radius, } \\
\text { km }\end{array}$ & LLR & p Value & $\mathbf{R R}$ & Observed & Expected \\
\hline Cluster1 & $\begin{array}{l}\text { Addis Ababa, Oromia*, Amhara†, Tigray } \ddagger \text {, Afar§ and } \\
\text { Somali }\end{array}$ & 258 & 48.0 & $<0.001$ & 2.6 & 252 & 153 \\
\hline Cluster 2 & Oromia-West Arsi Zone & 0 & 11.9 & 0.003 & 8.7 & 9 & 1 \\
\hline Cluster 3 & $\begin{array}{l}\text { Gambela-Anuak and Majanger Zones SNNPR-Sheka, } \\
\text { Bench maji and Keffa Zones }\end{array}$ & 49 & 6.0 & 0.413 & 3.1 & 13 & 4 \\
\hline Cluster 4 & SNNPR-Gedio Zone & 0 & 4.9 & 0.719 & 4.3 & 7 & 2 \\
\hline Cluster 5 & SNNPR-KT Zone & 0 & 3.7 & 0.975 & 3.1 & 8 & 3 \\
\hline Cluster 6 & Oromia-Borena Zone & 0 & 3.1 & 0.996 & 3.0 & 7 & 2 \\
\hline
\end{tabular}

*East Shewa, West Shewa, South West Shewa, North Shewa, Oromia Special Zone, Horo Guduru, parts of East Wollega, parts of West Hararge Zones.

†North Shewa Special Zone, South Wollo, East Gojjam, West Gojjam, South Gondar, Eastern parts of North Gondar, Wag Hemra and Agew Awi Zones.

$\ddagger$ South Tigray Zone.

§Zone 1 , zone 2 and zone 3.

TSite zone.

LLR, log likelihood ratio; KT, Kembata Tembaro; RR, relative risk; SNNPR, Southern Nations, Nationalities, and Peoples' Region.

location that found in Oromia administrative region, West Arsi Zone, was circled with 8.7 relative risk and 11.9 LLR.

\section{Factors associated with HIV infection}

During bivariate analysis, ever use of khat and migration status had no statistically significant association with HIV based on the cut-off point $\mathrm{p}$ value $<0.25$. Variables including exposure to mass media, ever use of alcohol, mobile workers and comprehensive knowledge of HIV were associated with HIV in the bivariate analysis; however; they were not found to be statistically significant in the multivariable logistic regression model.

As shown in the multivariable analysis of table 3 and figure 3 , those individuals who were in the middle, richer and richest wealth quintiles had higher odds of having HIV compared with the poorest wealth quintile $($ adjusted OR $(\mathrm{AOR})=1.7 ; 95 \%$ CI $(1.01$ to 2.99$))$, $(\mathrm{AOR}=2.3 ; 95 \%$ CI $(1.37$ to 3.90$))$ and $(\mathrm{AOR}=4.1 ; 95 \%$ CI (2.28 to 7.39)), respectively. The odds of having HIV were higher among urban residents compared with their rural counterparts $(\mathrm{AOR}=1.8 ; 95 \%$ CI (1.24 to 2.66)) .

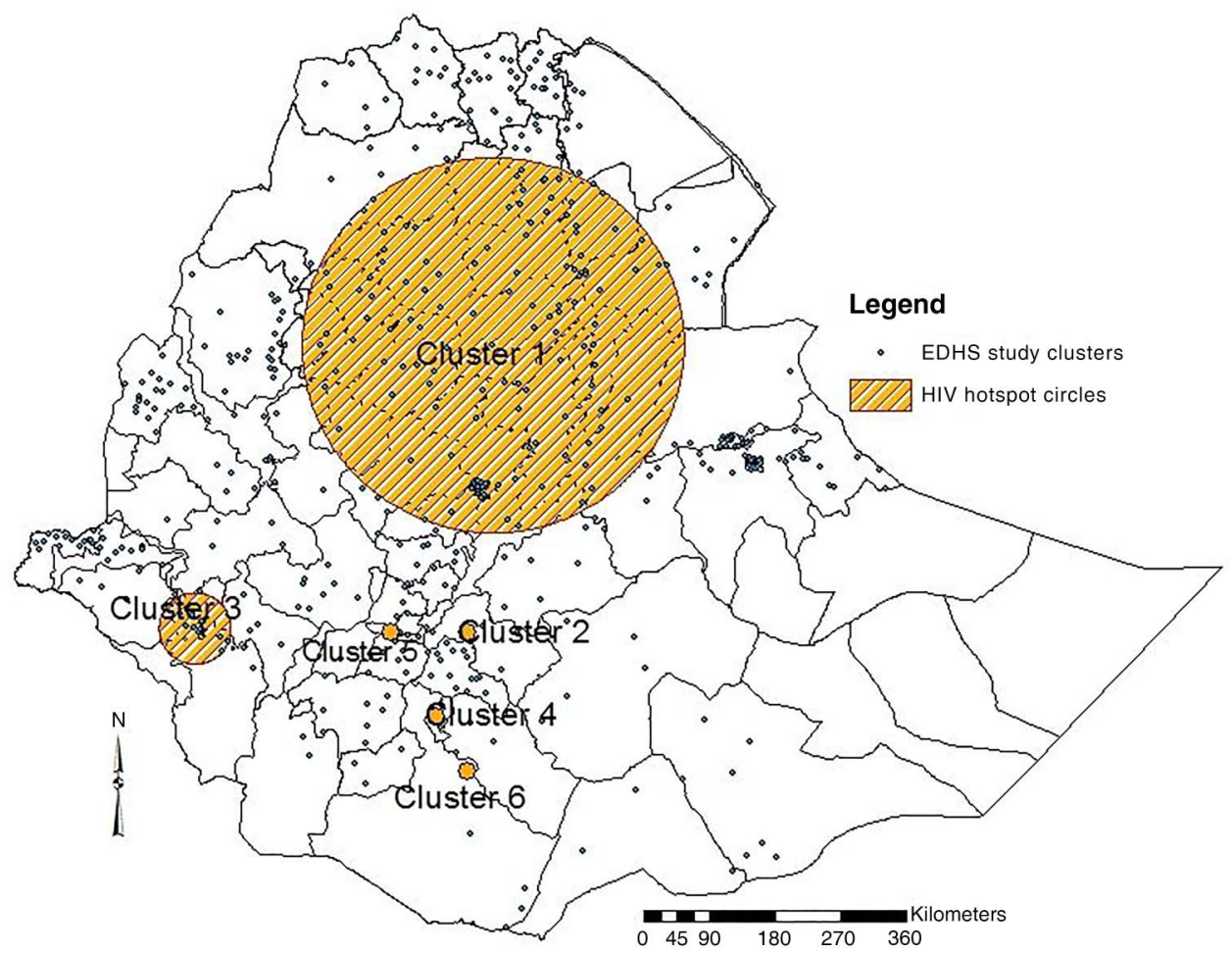

Figure 2 HIV hotspot clusters identified at zonal level using SaTScan spatial analysis tool, in Ethiopia 2011 (EDHS, Ethiopian Demographic and Health Survey). 
Table 3 Bivariate and multivariable logistic regression analysis to identify factors associated with HIV infection among adult population in Ethiopia, 2011

\begin{tabular}{|c|c|c|}
\hline Independent risk factors & Crude OR with $95 \% \mathrm{Cl}$ & AOR with $95 \% \mathrm{CI}$ \\
\hline \multicolumn{3}{|l|}{ Wealth index } \\
\hline Poorest & 1.00 & 1.00 \\
\hline Poorer & $1.0(0.58$ to 1.83$)$ & 0.9 (0.50 to 1.75$)$ \\
\hline Middle & $1.6(0.97$ to 2.72$)$ & $1.7(1.01 \text { to } 2.99)^{*}$ \\
\hline Richer & $2.4(1.51 \text { to } 3.96)^{\star \star}$ & $2.3(1.37 \text { to } 3.90)^{*}$ \\
\hline Richest & $9.6(6.23 \text { to } 14.70)^{\star \star}$ & $4.1(2.28 \text { to } 7.39)^{\star *}$ \\
\hline \multicolumn{3}{|l|}{ Residence } \\
\hline Rural & 1.00 & 1.00 \\
\hline Urban & $6.4(5.28 \text { to } 7.83)^{\star *}$ & $1.8(1.24 \text { to } 2.66)^{*}$ \\
\hline \multicolumn{3}{|l|}{ Administrative regions } \\
\hline Tigray & 1.00 & 1.00 \\
\hline Afar & $1.0(0.36$ to 2.66$)$ & $2.0(0.63$ to 5.99$)$ \\
\hline Amhara & $0.9(0.60$ to 1.27$)$ & $1.2(0.80$ to 1.91$)$ \\
\hline Oromia & $0.5(0.37 \text { to } 0.79)^{*}$ & $1.1(0.73$ to 1.78$)$ \\
\hline Somali & 0.8 (0.38 to 1.82$)$ & $1.2(0.47$ to 3.27$)$ \\
\hline Benishangul-Gumuz & $0.7(0.27$ to 2.06$)$ & $1.4(0.47$ to 4.24$)$ \\
\hline SNNPR & $0.57(0.37 \text { to } 0.87)^{\star}$ & $1.0(0.57$ to 1.59$)$ \\
\hline Gambela & $3.8(1.78 \text { to } 8.33)^{\star}$ & $4.1(1.70 \text { to } 9.88)^{*}$ \\
\hline Harari & $1.6(0.43$ to 6.19$)$ & 1.4 (0.33 to 5.97$)$ \\
\hline Addis Ababa & $2.9(1.96 \text { to } 4.43)^{\star \star}$ & 1.5 (0.90 to 2.36$)$ \\
\hline Dire Dawa & $2.2(0.82$ to 6.04$)$ & $1.5(0.50$ to 4.55$)$ \\
\hline \multicolumn{3}{|l|}{ Marital status } \\
\hline Never married & 1.00 & 1.00 \\
\hline Currently married & $3.3(2.37 \text { to } 4.58)^{\star \star}$ & 1.5 (0.88 to 2.40$)$ \\
\hline Formerly married & $16.9(11.94 \text { to } 24.07)^{\star *}$ & $4.2(2.48 \text { to } 7.16)^{\star \star}$ \\
\hline \multicolumn{3}{|l|}{ Education } \\
\hline No formal education & 1.00 & 1.00 \\
\hline Primary education & $1.4(1.12 \text { to } 1.73)^{\star}$ & $1.7(1.32 \text { to } 2.26)^{\star *}$ \\
\hline Secondary and higher & $2.2(1.68 \text { to } 2.85)^{\star *}$ & $1.6(1.11 \text { to } 2.36)^{*}$ \\
\hline \multicolumn{3}{|l|}{ Religion } \\
\hline Christian & 1.00 & 1.00 \\
\hline Muslim & $0.4(0.29 \text { to } 0.51)^{\star *}$ & $0.6(0.41 \text { to } 0.83)^{*}$ \\
\hline Others including traditional religions & $0.8(0.40$ to 1.58$)$ & $1.9(0.82$ to 4.19$)$ \\
\hline \multicolumn{3}{|l|}{ Lifetime sexual partners } \\
\hline Single & 1.00 & 1.00 \\
\hline Multiple & $4.1(3.30 \text { to } 5.06)^{\star \star}$ & $3.4(2.64 \text { to } 4.28)^{\star \star}$ \\
\hline \multicolumn{3}{|l|}{ Age groups } \\
\hline $15-19$ & $0.1(0.07 \text { to } 0.24)^{\star *}$ & $0.1(0.02 \text { to } 0.66)^{*}$ \\
\hline $20-24$ & $0.5(0.31 \text { to } 0.77)^{*}$ & $0.7(0.42$ to 1.20$)$ \\
\hline $25-29$ & $1.5(1.06 \text { to } 2.15)^{\star}$ & $1.7(1.15 \text { to } 2.52)^{*}$ \\
\hline $30-34$ & $2.0(1.41 \text { to } 2.90)^{\star *}$ & $2.0(1.32 \text { to } 2.91)^{*}$ \\
\hline $35-39$ & $2.2(1.55 \text { to } 3.17)^{\star \star}$ & $2.1(1.40 \text { to } 3.07)^{\star \star}$ \\
\hline $40-44$ & $1.4(0.94$ to 2.19$)$ & $1.4(0.89$ to 2.21$)$ \\
\hline 45-49 & 1.00 & 1.00 \\
\hline \multicolumn{3}{|l|}{ Occupation } \\
\hline Not working & 1.00 & 1.00 \\
\hline Corporate and general managers & $0.9(0.12$ to 6.42$)$ & $1.0(0.76$ to 1.43$)$ \\
\hline Teaching and associate professions & $1.5(0.78$ to 2.99$)$ & $0.2(0.03$ to 1.53$)$ \\
\hline Health and life science workers & $1.9(0.57$ to 6.04$)$ & $0.5(0.22$ to 1.06$)$ \\
\hline Construction and engineering workers & $2.3(0.44$ to 11.81$)$ & $0.7(0.21$ to 2.49$)$ \\
\hline Frontline service workers & $3.2(2.08 \text { to } 5.02)^{\star \star}$ & $0.4(0.05$ to 3.95$)$ \\
\hline Sales workers & $2.1(1.58 \text { to } 2.76)^{* *}$ & $0.7(0.41$ to 1.20$)$ \\
\hline Agricultural workers & $0.4(0.26 \text { to } 0.52)^{\star *}$ & 0.7 (0.45 to 1.13$)$ \\
\hline Daily labourers & $0.5(0.36 \text { to } 0.82)^{* *}$ & $0.6(0.35 \text { to } 0.87)^{*}$ \\
\hline Merchants & $4.3(3.22 \text { to } 5.71)^{\star \star}$ & $1.8(1.30 \text { to } 2.43)^{\star \star}$ \\
\hline Mobile workers including drivers and operators & $4.6(2.46 \text { to } 8.69)^{\star *}$ & $1.1(0.56$ to 2.27$)$ \\
\hline
\end{tabular}


Table 3 Continued

\section{Independent risk factors}

Crude OR with $95 \% \mathrm{CI}$

AOR with $95 \% \mathrm{Cl}$

Sex

Male

1.00

1.00

Female

$1.8(1.49 \text { to } 2.24)^{\star \star}$

$1.9(1.44 \text { to } 2.63)^{\star \star}$

${ }^{*} p<0.01,{ }^{* *} p<0.001$

AOR, adjusted OR; SNNPR, Southern Nations, Nationalities, and Peoples' Region.

Compared with Tigray regional state, the odds of having HIV were higher in Gambela administrative region $(\mathrm{AOR}=4.1 ; 95 \%$ CI $(1.70$ to 9.88$))$. Those individuals who were formerly married had higher odds compared with never married individuals $(\mathrm{AOR}=4.2 ; 95 \%$ CI $(2.48$ to 7.16)). Similarly, those individuals who had attended primary education had $(\mathrm{AOR}=1.7 ; 95 \%$ CI $(1.32$ to 2.26)) and secondary and higher education had $(\mathrm{AOR}=1.6$; $95 \%$ CI (1.11 to 2.36)) times higher odds to have HIV infection compared with those who had no formal education.

Those Islamic religion followers were less likely to have HIV infection compared with Christian religions followers $(\mathrm{AOR}=0.58 ; 95 \%$ CI $(0.41$ to 0.83$)$ ). The odds of having HIV infection were higher among adults who had multiple lifetime sexual partners than individuals with only one lifetime partner (AOR=3.4; 95\% CI (2.64 to 4.28)). Compared with adults in the age group of 4549 years, those adults in the age group of 15-19 years had less odds of having HIV infection(AOR $=0.12 ; 95 \%$ CI $(0.02$ to 0.66$))$. However, adults in the age groups of 25-29, 30-34 and 35-39 years were more likely to have HIV infection compared with adults in the age group of
45-49 years $\quad(\mathrm{AOR}=1.7 ; \quad 95 \% \quad \mathrm{CI} \quad(1.15$ to 2.52$))$, $(\mathrm{AOR}=2.0 ; 95 \%$ CI $(1.32$ to 2.91$))$ and $(\mathrm{AOR}=2.1 ; 95 \%$ CI (1.42 to 3.07$)$ ), respectively.

Among the occupational categories, daily labourers had statistically significant lower odds of having HIV infection compared with non-working individuals (AOR $=0.55 ; 95 \%$ CI $(0.35$ to 0.87$)$ ). However, merchants had higher odds of having HIV infection compared with those adults who were not-working $(\mathrm{AOR}=1.8 ; 95 \%$ CI (1.30 to 2.43)). The odds of having HIV infection among females were higher compared with male counterparts $(\mathrm{AOR}=1.9 ; 95 \% \mathrm{CI}(1.44$ to 2.63$))$. The vertical line in figure 3 represents OR of 1 . Variables with OR on this reference line have no association with HIV. Variables with OR above the reference line have a higher odds of acquiring HIV whereas variables with OR below the reference line have lower odds of having HIV infection.

\section{DISCUSSION}

This study found remarkable variations of HIV prevalence in the geographic and subpopulation groups in

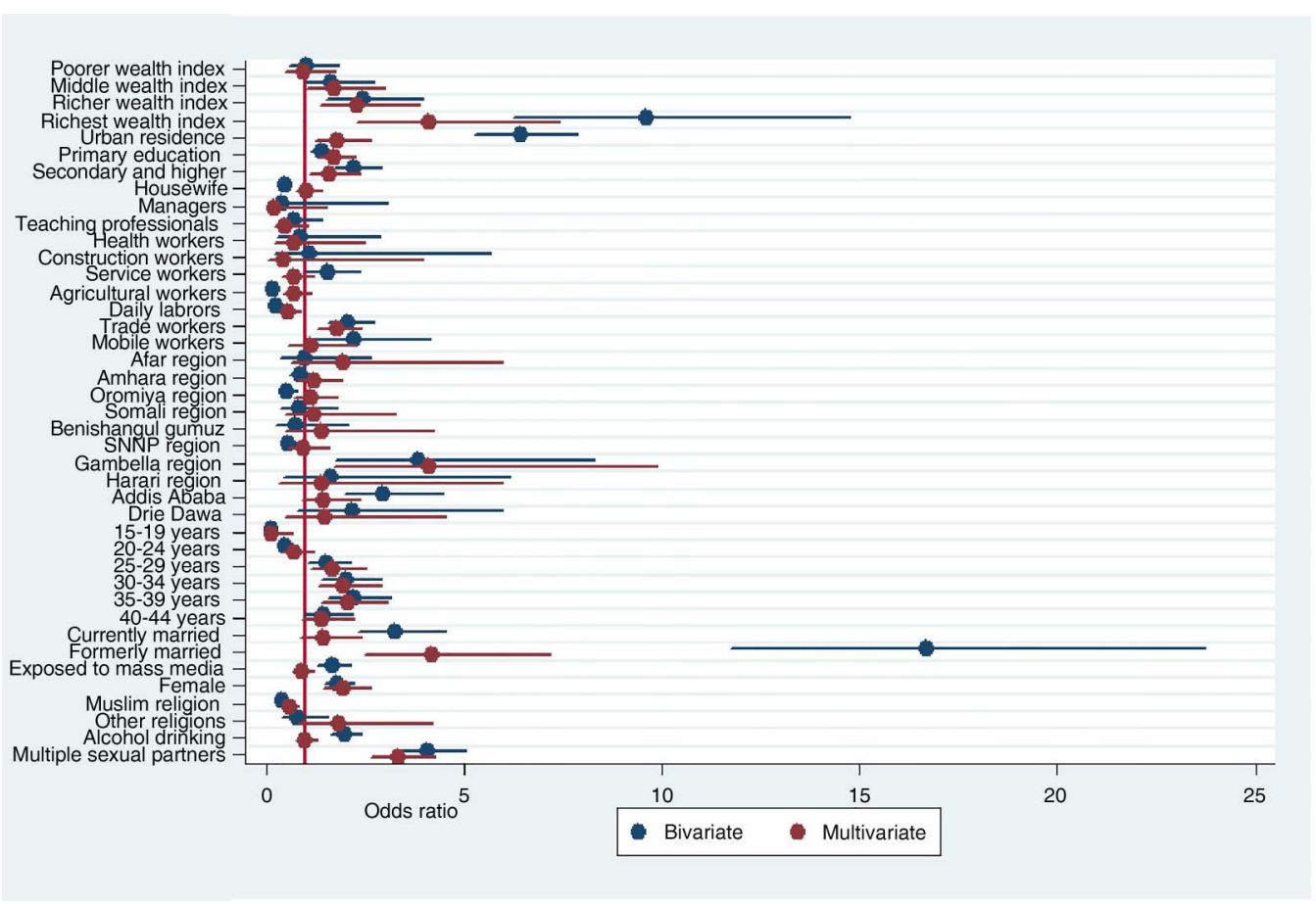

Figure 3 Odds ratio of HIV infection and associated factors among adults in Ethiopia, 2011. 
Ethiopia. The result is similar with findings in other countries that indicated microlevel epidemics hidden by low national HIV prevalence. ${ }^{11}{ }^{14} 16$ This suggests that the HIV epidemic in certain localities could cause an emergence or re-emergence of the epidemic if not well addressed in the subgeographic and population groups.

The highest prevalence of HIV found in Gambela administrative region which could be attributed by higher prevalence of traditional practices such as polygamy and levirate marriage. ${ }^{28}$ It could also be explained by the fact that Gambela is one of the regions in Ethiopia where male circumcision is least practiced thought it has proved protective effect on HIV infection. ${ }^{29} 30$ The next highest prevalence of HIV was found in Addis Ababa. This might be due to the fact that the city contains a relatively large segment of commercial sexual workers of various types. ${ }^{31}$ Furthermore, Addis Ababa is a rapidly growing city that attracts various types of tourists which, in turn, may contribute to the HIV epidemic. Evidence showed that tourism has effect on addictive substance and drug use ${ }^{32}$ and it is associated with higher odds of HIV infection. ${ }^{33}$ Similarly, commercial sex workers target tourists for economic gain and this could transport diseases back into other communities. ${ }^{34}$ Furthermore, a transgenerational and transactional sexual practices are very common in places of Dukem and Bishoftu towns which are found nearby Addis Ababa. ${ }^{35}$ Dire Dawa administrative city also has a high prevalence of HIV which could be attributed by the fact that the town has been serving as a rest centre for truck drivers from Djibouti port to Addis Ababa and who, along the way, frequent sex workers. This study also revealed that there are certain occupational groups which had a high prevalence of HIV. A population group that have higher than average HIV prevalence when compared with the general population is labelled as most-at-risk populations (MARPs). ${ }^{36}$ Accordingly in this study, those occupational groups including merchants, mobile workers, service workers, construction and engineering workers might be additional MARPs in addition to the previously described populations in Ethiopia.

The multivariable analysis found that HIV prevalence was associated with wealthier groups. There are different arguments either poverty or wealth is driving HIV transmission. ${ }^{37}$ The relationship between HIV infection and wealth quintile did not show consistent trends in many other countries. ${ }^{21}$ In this study, those individuals who were in the wealthier category had higher odds of having HIV infection compared with the poorest category. Similar findings were reported from the decomposition analysis from sub-Sahara African countries. ${ }^{18}$ Other studies from developing countries also showed that HIV is more prevalent in wealthier groups. ${ }^{19} 2138-40$ A recent meta-analysis study revealed that risky sexual behaviour is associated with high economic status. ${ }^{41} \mathrm{~A}$ study in Addis Ababa among taxi drivers and assistants also found income as one of the factors associated with HIV risk behaviours. ${ }^{42}$

The present study found higher odds of HIV infection among educated adults. Similarly, a systemic review studies showed that high HIV prevalence was found among more highly educated groups than less educated groups. ${ }^{39} 4344$ The highly educated groups had more sexual partners, non-marital sexual partners and a greater likelihood of premarital sex than less educated groups. ${ }^{40} 414546$ A study conducted in Ethiopia among women showed that HIV prevalence declined overtime among no formal and secondary education groups, but not among the primary educated group. ${ }^{45}$ The study also come up with little evidence to show significant difference in the prevalence change overtime by educational attainment. ${ }^{44}$

In this analysis, the odds of having HIV infection was $80 \%$ higher among urban residents compared with their rural counterparts. This could be explained by the presence of large numbers of MARPs in urban than rural areas. Urban residency was also associated with risky sexual behaviours in other developing countries. ${ }^{41}$ As expected, this study found that those individuals who had multiple sexual partners had higher odds of HIV infection as compared with individuals who had single lifetime sexual partners. This finding is consistent with several studies elsewhere. ${ }^{47-49}$ The present study showed that formerly married adults had higher odds of having HIV infection compared with non-married individuals. A similar finding was reported from many studies elsewhere. $^{22-24} 50$ Those formerly married adults found to engage in risky sexual behaviours. ${ }^{51} 52$ This is explained by the fact that divorced and widowed women usually suffering from economic challenges that could lead some to have risky sexual behaviours such as prostitution or sexual for goods and favours. An evidence revealed that divorced adults had higher risks of heavy alcohol consumption $^{53}$ and such drinking behaviour could result in HIV infection.

In our analysis, females had higher odds of having HIV infection compared with males. There are a lot of biological, socioeconomic and cultural risk factors that increase women's vulnerability to HIV acquisition. ${ }^{20}$ The first explanation could be the biological disadvantage of female's reproductive anatomy. Women are at a greater physiological risk of contracting HIV than men because of fluid receptors. This is in part because women have a greater mucosal surface area exposed to pathogens and infectious fluid for longer periods during sexual intercourse and are likely to experience tissue injury. ${ }^{20}$ Another possible explanation could be sex for money. Many women also engaged in sex work in exchange for money, goods, or other benefits. ${ }^{54}$ Gender inequality and gender-based violence placed women also at higher risk for HIV infection. ${ }^{45}$ Gender norms in some African countries promote multiple concurrent sexual partners for men while women are expected to be monogamous and unquestioning of their partner's behaviour. ${ }^{47-49}$ 
Public health implications

This study supports the hypothesis that risk factors for HIV are associated with certain specific socioeconomic and demographic characteristics which could be targeted to improve existing public health prevention measures in the general population. In the absence of studies that attempted to quantify HIV infection by subpopulation group and spatial variations, the present study provides useful information for policy and programme actions. Among the occupational categories, merchants, construction and engineering workers, frontline service and mobile workers had high prevalence rates of HIV infection and need to be considered as a key population for HIV. In certain geographic clusters particularly in central and western parts of Ethiopia a statistically significant high HIV concentration was observed. This is evidence that the microepidemics started as localised in certain geographical locations and subpopulation groups in Ethiopia. Furthermore, this study showed that educated and wealthier groups had higher odds of having HIV infection than the less educated and poorer population categories. The most productive age group of 25-39 years is also found at risk for HIV infection which has its own development implications. Therefore, HIV is not only an issue of the health sector alone, it is a wide spectrum of development agenda. Monitoring the epidemics of HIV in accordance with population segmentation and localised intervention programmes would have a paramount importance rather than using the national prevalence as the key monitoring variable.

\section{CONCLUSION}

The prevalence of HIV was neither randomly nor uniformly distributed in Ethiopia. The HIV epidemic has concentrated in geographic areas of 25 administrative zones in Oromia, Amhara, Tigray, Afar and Somali regions. The epidemic is also concentrated among merchants, educated groups, females, wealthier individuals and urban residents. This study recommends the need to have spatial-based prevention strategies for specific population groups particularly focusing on regional and zonal geographic borders within the hotspot areas.

Acknowledgements The authors would like to acknowledge Lianna Tabar, WEEMA International, Brookline, MA, USA, for her language editing.

Contributors $\mathrm{YL}$ and $\mathrm{DH}$ conceptualised the study, performed the data analysis, made interpretations and drafted the manuscript. SB edited, interpreted the data and critically reviewed the manuscript. All the authors read the manuscript and approved the final version.

Funding This research received no specific grant from any funding agency in the public, commercial or not-for-profit sectors.

Competing interests None declared

Ethics approval Ethical clearance for the original survey was provided by the Ethiopian Public Health Institute (EPHI) Review Board, the National Research Ethics Review Committee (NRERC) at the Ministry of Science and Technology, the Institutional Review Board of ICF International and the Centers for Disease Control and Prevention (CDC); and the MACRO DHS.
Provenance and peer review Not commissioned; externally peer reviewed.

Data sharing statement No additional data are available.

Open Access This is an Open Access article distributed in accordance with the Creative Commons Attribution Non Commercial (CC BY-NC 4.0) license, which permits others to distribute, remix, adapt, build upon this work noncommercially, and license their derivative works on different terms, provided the original work is properly cited and the use is non-commercial. See: http:// creativecommons.org/licenses/by-nc/4.0/

\section{REFERENCES}

1. FHAPCO. Report on progress towards implementation of the UN Declaration of Commitment on HIVIAIDS. FHAPCO, 2010.

2. UNAIDS. Global Report: UNAIDS report on the global AIDS epidemic 2013. 2013. http://www.unaids.org/sites/default/files/en/ media/unaids/contentassets/documents/epidemiology/2013/gr2013/ UNAIDS_Global_Report_2013_en.pdf

3. $\mathrm{FMOH}$. Report on progress towards implementation of the UN Declaration of Commitment on HIV/AIDS. 2010. http://data.unaids. org/pub/Report/2010/ethiopia_2010_country_progress_report_en.pdf

4. Ethiopian Ministry of Health. Federal HIV/AIDS prevention and control office, national factsheet. 2010. http://www.etharc.org/ resources/healthstat/nationalfactsheet/13-nationalfactsheet2010

5. Federal Democratic Republic of Ethiopia. Country Progress Report on HIVIAIDS response. 2012.

6. UNAIDS. UNAIDS report on the global AIDS epidemic. Geneva: UNAIDS, 2012.

7. DeCock KM, Jaffe HW, Curran JW. The evolving epidemiology of HIV/AIDS. AIDS 2012;26:1205-13.

8. Asamoah-Odei E, Calleja JG, Boerma J. HIV prevalence and trends in sub-Saharan Africa: no decline and large sub-regional differences. Lancet 2004;364:35-40.

9. Shaikh N, Abdullah F, Lombard CJ, et al. Masking through averages: intra-provincial heterogeneity in HIV prevalence within the Western Cape. S Afr Med J 2006;96:538-43.

10. Wand H, Whitaker C, Ramjee G. Geoadditive models to assess spatial variation of HIV infections among women in local communities of Durban, South Africa. Int J Health Geogr 2011;10:28

11. Cuadros DF, Awad SF, Abu-Raddad LJ. Mapping HIV clustering: a strategy for identifying populations at high risk of HIV infection in sub-Saharan Africa. Int J Health Geogr 2013;12:28.

12. Wilson D, Halperin DT. Know your epidemic, know your response: a useful approach, if we get it right. Lancet 2008;372:423-6.

13. Sam D. Challenges of containing new HIV infections in Ethiopia: unacknowledged transmission route. Capstone Collection, 2013; Paper 2610.

14. Tanser F, Oliveira TD, Maheu-Giroux M, et al. Concentrated HIV subepidemics in generalized epidemic settings. Curr Opin HIV AIDS 2014;9:115-25.

15. Amar-Roze JM. Geographic inequalities in HIV infection and AIDS in sub-Saharan Africa. Soc Sci Med 1999;36:1247-56.

16. Wand $\mathrm{H}$, Ramjee $\mathrm{G}$. Targeting the hotspots: investigating spatial and demographic variations in HIV infection in small communities in South Africa. J Int AIDS Soc 2010;13:41.

17. Central Statistical Agency (CSA) Ethiopia. Ethiopia Demographic and Health Survey 2011. Addis Ababa, Ethiopia; Calverton, Maryland: CSA and ORC Macro, 2012.

18. Hajizadeh M, Heymann DSS, Nandi A. Socioeconomic inequalities in HIV/AIDS prevalence in sub-Saharan African countries: evidence from the Demographic Health Surveys. Int J Equity Health 2014;13:18.

19. Mishra V, Assche SB, Greener R, et al. HIV infection does not disproportionately affect the poorer in sub-Saharan Africa. AIDS 2007:21:S17-28.

20. Ramjee G, Daniels B. Women and HIV in sub-Saharan Africa. AIDS Res Ther 2013:10:30.

21. Parkhurst JO. Understanding the correlations between wealth, poverty and human immunodeficiency virus infection in African countries. Bull World Health Organ 2010;88:519-26.

22. Tenkorang EY. Marriage, widowhood, divorce and HIV risks among women in sub-Saharan Africa. Int Health 2014;6:46-53.

23. Kimani JK, Ettarh R, Ziraba AK, et al. Marital status and risk of HIV infection in slum settlements of Nairobi, Kenya: results from a cross-sectional survey. Afr J Reprod Health 2013;17:103-13.

24. Hazarika I. Risk factors for HIV-1 infection in India: evidence from the National Family Health Survey. Int J STD AIDS 2012;23:729-35.

25. Kulldorf M. SaTScan 7.0: Software for the spatial and space-time scan statistics. Information Management Services Inc, 2006. 
26. Hosmer DW, Lemeshow S. Applied logistic regression. New York: John Wiley, 2000.

27. Hosmer D, Lemeshow S. Applied logistic regression. New York: John Wiley \& Sons, 1989.

28. Molla A, Gelaw B, Addis Z, et al. Marriage patterns and sero-prevalence of HIV infection at Gambella Administrative Region, Southwest Ethiopia. J Behav Health 2013;2:223-9.

29. Halperin DT, Bailey RC. Male circumcision and HIV infection: 10 years and counting. Lancet 1999;354:1813-15.

30. Szabo R, Short RV. How does male circumcision protect against HIV infection? BMJ 2000;320:1592.

31. Family Health International-Ethiopia. Mapping and census of female sex workers in Addis Ababa, Ethiopia. 2002. http://www.who. int/hiv/topics/vct/sw_toolkit/mapping_census_female_sex_workers_ ethiopia.pdf.

32. Guilamo-Ramos V, Lee JJ, Ruiz Y, et al. Illicit drug use and HIV risk in the Dominican Republic: tourism areas create drug use opportunities. Glob Public Health 2015;10:318-30.

33. Vlahov D, Robertson AM, Strathdee SA. Prevention of HIV infection among injection drug users in resource-limited settings. Clin Infect Dis 2010;50:S114-21.

34. Padilla MB, Guilamo-Ramos V, Bouris A, et al. HIV/AIDS and tourism in the Caribbean: an ecological systems perspective. Am J Public Health 2010;100:70-7.

35. Melkamu Y. Identifying at risk populations and HIV/AIDS referral services: baseline assessment for mobile counseling and testing program in the Oromia region of Ethiopia. Bethesda, MD: Private Sector Program (PSP)-Ethiopia project, Abt Associates Inc., 2007.

36. CDC. Developing new strategies to prevent the spread of HIV. http:// www.cdc.gov/globalhealth/countries/southafrica/what/at_risk.htm

37. Gillespie S, Kadiyala S, Greener R. Is poverty or wealth driving HIV transmission. AIDS 2007;21:S5-16.

38. Awusabo-Asare K, Annim SK. Wealth status and risky sexual behaviour in Ghana and Kenya. Appl Health Econ Health Policy 2008;6:27-39.

39. Berhan Y, Berhan A. Meta-analysis on risky sexual behaviour of men: consistent findings from different parts of the world. AIDS Care 2013;25:151-9.

40. Berhan A, Berhan Y. A meta-analysis on higher-risk sexual behavior of women in 28 third world countries. World J AIDS 2012;2:78-88.

41. Berhan $Y$, Berhan A. A meta-analysis of risky sexual behaviour among male youth in developing countries. AIDS Res Treat 2015;2015:580961.
42. Lakew $\mathrm{Y}$, Tamene H. HIV related risk behaviours among taxi drivers and their assistants in Addis Ababa, Ethiopia: descriptive cross-sectional survey. BMC Public Health 2014;14:330.

43. Hargreaves JR, Bonell CP, Boler T, et al. Systematic review exploring time trends in the association between educational attainment and risk of HIV infection in sub-Saharan Africa. AIDS 2008;22:403-14.

44. Hargreaves JR, Davey C, Fearon E, et al. Trends in socioeconomic inequalities in HIV prevalence among young people in seven countries in Eastern and Southern Africa. PLOS ONE 2015;10: e0121775.

45. Hargreaves JR, Glynn JR. Educational attainment and HIV-1 infection in developing countries: a systematic review. Trop Med Int Health 2002;7:489-98.

46. Fortson JG. The gradient in sub-Saharan Africa: socioeconomic status and HIV/AIDS. Demography 2008;45:303-22.

47. Higgins JA, Hoffman S, Dworkin SL. Rethinking gender, heterosexual men and women's vulnerability to HIV/AIDS. Am J Public Health 2010;100:435-45.

48. Vyas S, Watts C. How does economic empowerment affect women's risk of intimate partner violence in low and middle income countries? A systematic review of published evidence. J Int Dev 2009;21:577-602.

49. Gupta GR. How men's power over women fuels the HIV epidemic: it limits women's ability to control sexual interactions. BMJ 2002;324:183.

50. Mermin J, Musinguzi J, Opio A, et al. Risk factors for recent HIV infection in Uganda. JAMA 2008;300:540-9.

51. Kassa M, Tesfaye E, Alamrew Z. Risky sexual behaviour among big construction enterprise workers; Bahir Dar City, Amhara Regional State, Northwest Ethiopia. Int J Clin Med 2013;4:296-303.

52. Tadesse G, Yakob B. Risky sexual behaviors among female youth in Tiss Abay, a semi-urban area of the Amhara Region, Ethiopia. PLoS ONE 2015;10:e0119050.

53. Power C, Rodgers B, Hope S. Heavy alcohol consumption and marital status: disentangling the relationship in a national study of young adults. Addiction 1999;94:1477-87.

54. Vandepitte J, Lyerla R, Dallabetta G, et al. Estimates of the number of female sex workers in different regions of the world. Sex Transm Infect 2006;82:18-25.

55. Murphy EM, Greene ME, Mihailovic A, et al. Was the "ABC" approach (Abstinence, Being Faithful, Using Condoms) responsible for Uganda's Decline in HIV? PLoS Med 2006;3:e379. 